\title{
Recovery of function after brain damage: On deposits to the memory bank
}

\author{
T. E. LeVERE, E. T. CHAPPELL, and N. DAVIS LeVERE \\ North Carolina State University, Raleigh, North Carolina
}

\begin{abstract}
The availability of spared memories following neocortical injury has been shown to be related to the similarity of preoperative learning and postoperative recovery situations. In the present research we questioned whether the nature of the memory itself might also be an important determinant of the availability of spared memories following neocortical brain injury. It was found that the changes that interfere with the postoperative retrieval of memories of behaviors learned for a single motivational state do not interfere with the postoperative retrieval of memories of behaviors learned to satisfy two concurrent motivational states. Apparently, the nature of the memory is an important determinant of its availability following neocortical injury.
\end{abstract}

Lashley's (1935) demonstration that posterior visual decortication will completely disrupt a preoperatively learned visual behavior has been replicated many times (see D. R. Meyer \& P. M. Meyer, 1977). Lashley's interpretation of this result as a lesion-induced memory loss has not, however, enjoyed the same degree of agreement. For example, experiments with amphetamine (Braun, P. M. Meyer, \& D. R. Meyer, 1966) have shown that this drug will facilitate the postoperative recovery, but not the original acquisition, of a brightness discrimination. Moreover, striate lesioned rats require a significantly greater number of trials to reestablish the reversal of a brightness discrimination that was learned preoperatively than they do when the reward contingencies are identical to the preoperatively learned behavior (LeVere \& Morlock, 1973, 1974). These results, and others summarized by LeVere (1975), could occur only if the memories of the preoperatively learned behavior were spared even though the neocortically injured rat was initially unable to perform the behavior.

These data have two important ramifications concerning recovery of function. First, as suggested over a decade ago by D. R. Meyer (1972), the recovery of learned behaviors may be not so much a process of relearning what was lost but rather of remembering what was spared. Second, and because of this, the progress of the recovery process should be directly dependent upon the availability of spared memories.

Unfortunately, we know very little about the parameters that determine the postoperative availability of spared memories except that a high degree of parity between the pre- and postoperative training situations is apparently required. For example, if either the extrinsic stimulus con-

This research was supported by Research Grant NS-12459 from the National Institute of Neurological and Communicative Disorders and Stroke, H.H.S., to T. E. LeVere. The authors' mailing address is: Neuropsychology Laboratory, Department of Psychology, Box 7801, North Carolina State University, Raleigh, NC 27695-7801. ditions (LeVere, Davis, \& Fontaine, 1977) or the animal's intrinsic motivational state (LeVere \& Davis, 1977) are changed between preoperative learning and postoperative recovery, then the reversal impairment noted by LeVere and Davis (1977) and LeVere and Morlock $(1973,1974)$ does not occur. This lack of interference during postoperative reversal training clearly indicates that the spared memory was unavailable to the lesioned animal when the conditions of postoperative recovery were not the same as the conditions of preoperative learning. The present research used this finding to further investigate what might determine the postoperative availability of spared memories.

Our question was whether the nature of the memory itself might also determine its availability following neocortical injury. Specifically, we wished to know whether the memory of a behavior learned to satisfy two concurrent motivational states may be more available after brain injury than the memory of a behavior learned to satisfy a single motivational state. Our procedure was a variation of the LeVere and Davis (1977) experiment, except that the rats preoperatively learned the brightness discrimination for concurrent food and shock-escape rewards. Following visual decortication, we changed the motivational conditions by requiring that the animals recover the brightness discrimination, or its reversal, for either just food reward or just shock-escape reward. Our prediction was that if the nature of a memory is important to its availability, then we might expect a significant reversal impairment even though the postoperative recovery conditions were changed. On the other hand, if the nature of a memory is unimportant, then we should replicate the LeVere and Davis (1977) result and not find a reversal impairment.

\section{METHOD}

\section{Subjects \\ Seventy-four male hooded rats that had been born in our laboratory were 90 to 120 days old when introduced into the experiment. The colony}


is maintained on a 10-/14-h reversed day/night cycle, and all animals are group-caged until participating in an experiment. All rats had free access to food and water except during water-reward training, when they were maintained on a 23 -h water-deprivation schedule.

\section{Apparatus}

The animals were trained in our Yerkes simultaneous two-choice brightness-discrimination apparatus, previously described by LeVere and Morlock (1973). In general, this apparatus consists of a start compartment, a choice area, and two goalboxes. The walls of the apparatus are black plastic, and the roof is clear plastic. The floors of the start compartment and choice area are brass rods, and floors of the goal areas are solid plastic. The rat gains access to the correct goal area by knocking down a translucent door at its entrance. The entrance door to the incorrect goal area is always locked. The brightness cues the rat learns to discriminate are produced by transilluminating the goalbox doors with $100-W$ lamps mounted at the end of enclosed tunnels extending $60 \mathrm{~cm}$ backward from the clear plastic rear wall of each goal area. The light from these lamps is restricted with apertures to produce $64 \mathrm{fL}$ for the brighter cue and $1 \mathrm{fL}$ for the dimmer cue. As the animal enters the correct goal area, both discriminative cues are immediately extinguished.

\section{Procedure}

Initially, all animals were water deprived and trained, with intermediate brightness cues ( $8 \mathrm{fL}$ ), to run from the start compartment and enter the goal areas to obtain water reward. Following this, the animals were trained on the two-choice brightness discrimination for water reward and, at the same time, to avoid/escape mild footshock $(.2 \mathrm{~mA})$ on a schedule of 10 trials/day, 7 days/week. Thirty-five of the animals were trained to choose the brighter discriminative cue; the remaining 39 animals were trained to choose the dimmer discriminative cue. On each trial, a pulsating footshock ( $0.5 \mathrm{sec}$ on, $0.5 \mathrm{sec}$ off $)$ was initiated immediately after the rat was placed in the start compartment and the guillotine door was raised. This footshock continued until the rat entered the correct goal area to obtain a small quantity of water reinforcement. Incorrect responses, that is attempts to enter the locked goal area, were punished by steady footshock until the rat corrected its error. Criterion was set at nine first-choice correct responses with a day's training.

Within $48 \mathrm{~h}$ of criterion performance, each animal was subjected to posterior visual decortication. The surgery was accomplished by aspiration after the subject was deeply anesthetized with sodium pentobarbital. The lesions were intended to include all neocortex receiving visual thalamic projections, as described by Hughes (1977), so all neocortex posterior to a line beginning at bregma and becoming tangential to the rhinal fissure was removed. After surgery, all animals received an intramuscular injection of a broad-band antibiotic. Each animal then had a 2-week rest before beginning postoperative training. A 23-h waterdeprivation regimen was initiated on the 12 th postoperative day for the animals that were to be retrained for water reward.

For postoperative recovery training, one-half of the animals preoperatively trained with the brighter cue correct were water deprived and retrained only for water reinforcement; the other half remained satiated and were retrained only to escape/avoid footshock. One half of the wateronly group and one-half of the shock-only group were retrained on the originally learned discrimination; the other half were retrained on the reversal of the original discrimination. The animals preoperatively trained with the dimmer cue correct were similarly partitioned. To control for differences in original acquisition, individual animals were assigned to one of these eight terminal experimental groups on the basis of preoperative errors to criterion. With the exceptions of the reversed discrimination for some animals and the change to a single motivational state for all animals, the postoperative retraining procedure was the sarne as that described for preoperative acquisition and was carried to the same criterion.

As each animal completed postoperative training, it was again anesthetized with sodium pentobarbital and perfused with saline followed by buffered Formalin. The brain was removed and the extent of the lesion was drawn on surface diagrams with the aid of a dissecting microscope. The brain was then sunk in a sucrose solution and cut into $50-\mu$ frontal sections on a freezing microtome. Every fifth section through the neocortical lesion and the dorsal lateral geniculate nucleus was saved and stained with cresyl violet.

\section{RESULTS}

\section{Histology}

Surface diagrams of the rats sustaining the largest and smallest neocortical lesions are shown in Figure 1. An analysis of variance indicated that there were no differences in lesion size between the eight experimental groups described above ( $\mathrm{F}$ less than 1 ).

Light microscopic analysis revealed that all six neocortical layers were completely destroyed in all animals. There was no evidence of bilateral invasion of hippocampus or other subcortical structures. In all cases, there was complete degeneration within the dorsal lateral geniculate nucleus while its ventral portion appeared normal. Other thalamic structures, such as the lateral posterior nucleus, showed some evidence of retrograde degeneration, although not nearly as extensive as that observed in the LGNd.

\section{Behavior}

The overall mean error score for preoperative original learning was 14.1 , with a mean error score range of 12.3 to 15.8 for the animals ultimately assigned to the eight postoperative experimental groups. An analysis of variance computed on these preoperative data revealed no significant differences $(F<1)$.

To evaluate the hypothesis under test, postoperative error scores were collapsed into a $2 \times 2$ ANOVA. The main factors of this analysis were postoperative motivation (shock vs. water) and type of problem (nonreversal vs. reversal). Figure 2 graphically presents the results of this analysis. As is clear from this figure, the present data do not replicate our earlier findings (LeVere \& Davis, 1977) inasmuch as changing motivation between preoperative learning and postoperative recovery did not prevent the preoperatively established memories from interfering with reversal training. Apparently, under these conditions, the

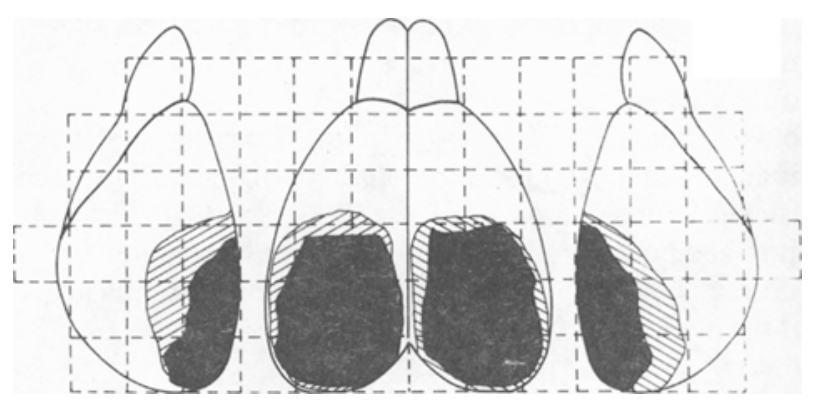

Figure 1. Diagrams of the surface destruction for the animal sustaining the smallest lesion (hatched) and the animal sustaining the largest lesion (black). 


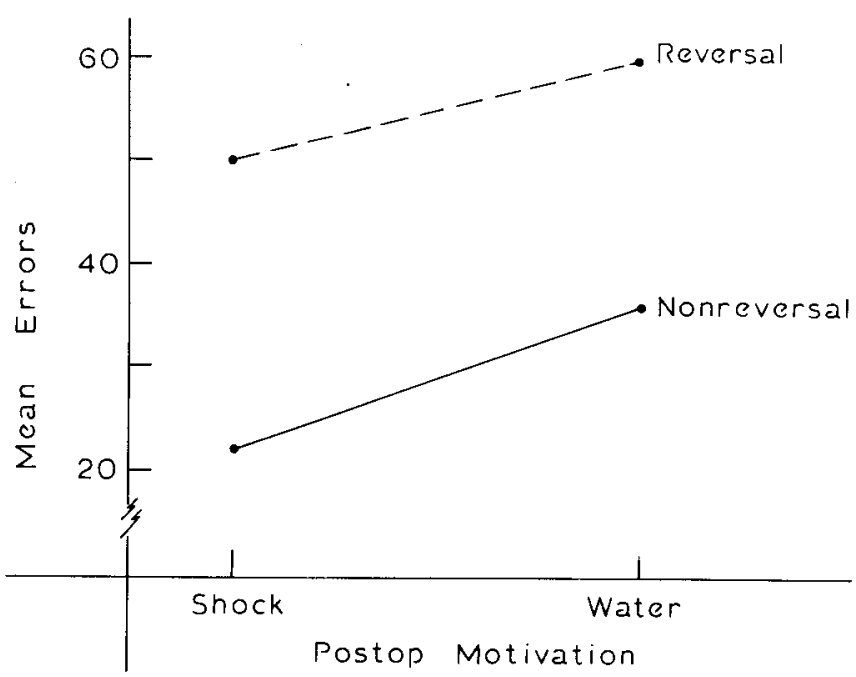

Figure 2. Mean error scores to criterion for postoperative nonreversal and reversal training when the animals were trained under either just water or just shock motivation.

memories of the preoperative habit were spared and were available to the striate lesioned animal. Concerning the ANOVA, both main factors were significant $[F(1,70)=$ 4.97 and $F(1,70)=22.68$, respectively, for motivation and type of problem], but the interaction was not significant $(\mathrm{F}<1)$.

\section{DISCUSSION}

That neocortical injury will disrupt preoperatively learned behaviors is well known. That it does so is perplexing. It is perplexing because there is now considerable evidence that neocortical injury does not necessarily destroy the capacity to perform the behavior or the memories of the previously learned behavior (see LeVere, 1980, for summary). Yet, even with this degree of morphological and functional sparing, there is still a severe postinjury behavioral deficit which can be corrected only with specific training (see, e.g., Davis \& LeVere, 1982).

It is important to remember, however, that the spared memories of preoperatively learned behaviors are very difficult for the lesioned animal to retrieve. In fact, it is only under rather extreme experimental circumstances, involving drugs or special training situations, that the existence of these spared memories can be demonstrated. It nonetheless remains true, however, that the memories of learned behaviors do survive neocortical injury, and if the determinants of their availability were understood, then the fundamental consequences of brain injury and their reversal would also be better understood.

Our previous research has indicated one determinant of the availability of spared memories-namely parity between the original preoperative learning situation and the postoperative conditions under which the animal is required to recover the learned behavior. Our present research suggests another. This is that the nature of the memory itself may also determine its availability following neocortical injury. This suggestion is based on our previous finding that changing the motivational conditions between preoperative original learning and postoperative recovery will prevent spared memories from interfering with postoperative reversal training (LeVere \& Davis, 1977). However, our present data show that if the original memory concerns a behavior learned to satisfy more than one motivational state, then this memory can be retrieved following neocortical injury and will interfere with postoperative reversal training, even when motivation is changed. These results, of course, are reminiscent of Gazzaniga's (1974) suggestion that certain memories may have more than one route of access and that those that do are more resistant to the effects of brain damage. We also believe that our results support Gazzaniga's conclusion that multiple routes may also underwrite the reported resilience of overtrained behaviors following brain damage (Chow \& Survis, 1958; Lukaszewska \& Thompson, 1967; Orbach \& Fantz, 1958; Thatcher \& Kimble, 1966; Weese, Neimand, \& Finger, 1973).

There is one procedural point that must be considered before we can accept the suggestion that the nature of a memory may be a determinant of its availability following neocortical injury. The present paradigm was based on the finding that a change in motivation between preoperative learning and postoperative recovery can prevent the retrieval of the memories of preoperative learning as evidenced by a lack of interference during postoperative reversal training (LeVere $\&$ Davis, 1977). In the present experiment, we also change the subject's motivational condition between preoperative learning and postoperative recovery, but found that this did not prevent the preoperatively learned behavior from interfering with reversal training. However, although changing from concurrent water-shock motivation to either just water or just shock motivation is, from an operational point of view, a change in motivation, it may not be so from the rat's point of view. In fact, if the rat did not recognize the postoperative recovery conditions as being different from the conditions of preoperative learning, then it could be suggested that the present experiment was simply a replication of our original reversal training experiments (LeVere \& Morlock, 1973, 1974). However, if this is true, and it may well be, it does not change our conclusion that the nature of the memory determines its postoperative availability. The reason is that if the rat perceived postoperative recovery training as being similar to the preoperative learning, then what made it do so was the nature of the preoperative memory itself. Moreover, this broadens our finding, because it also means that it is the nature of the memory which determines whether a situational change will prevent postoperative memory retrieval. Or, put otherwise, from the point of view of recovery of function, it is the nature of the deposit which determines what may be withdrawn from the memory bank following brain injury. 


\section{REFERENCES}

Braun, J. J., Meyer, P. M., \& Meyer, D. R. (1966). Sparing of a brightness habit in rats following visual decortication. Journal of Comparative and Physiological Psychology, 61, 79-82.

Chow, K. L., \& SURvis, J. (1958). Retention of overlearned visual habit after temporal cortical ablation in monkey. Archives of Neurology and Psychiatry, 79, 640-646.

DAvIS, N., \& LEVERE, T. E. (1982). Recovery of function after brain damage: The question of individual behaviors or functionality. $E x$ perimental Neurology, 75, 68-78.

GaZZANIGA, M. S. (1974). Determinants of cerebral recovery. In D. B. Stein, J. J. Rosen, \& Butters (Eds.), Plasticity and recovery of function in the central nervous system. New York: Academic Press.

HUGHEs, H. G. (1977). Anatomical and neurobehavioral investigations concerning the thalamo-cortical organization of the rat's visual system. Journal of Comparative Neurology, 175, 311-335.

LASHLEY, K. S. (1935). The mechanism of vision: XII. Nervous structures concerned in habits based on reactions to light. Comparative Psychology Monographs, 11, 43-79.

LEVERE, T. E. (1975). Neural stability, sparing, and recovery of function after brain damage. Psychological Review, 82, 344-358.

LEVERE, T. E. (1980). Recovery of function after brain damage: A theory of the behavioral deficit. Physiological Psychology, 8, 297-308.

LEVERE, T. E., \& DAVIS, N. (1977). Recovery of function after brain damage: The motivational specificity of spared neural traces. Experimental Neurology, 57, 833-899.

LeVere, T. E., Davis, N., \& Fontaine, C. W. (1977). Recovery of function after brain damage: The extrinsic stimulus specificity of spared neural traces. Brain Research Bulletin, 3, 29-35.
LeVere, T. E., \& Morlock, G. W. (1973). The nature of visual recovery following posterior decortication in the hooded rat. Journal of Comparative and Physiological Psychology, 83, 62-67.

LEVERE, T. E., \& MORLOCK, G. W. (1974). The influence of preoperative learning on the recovery of a successive brightness discrimination following posterior neodecortication in the hooded rat. Bulletin of the Psychonomic Society, 4, 507-509.

LUKASZEWSKA, I., \& THOMPSON, R. (1967). Retention of an overtrained pattern discrimination following pretectal lesions in rats. Psychonomic Science, 8, 121-122.

MEYER, D. R. (1972). Access to engrams. American Psychologist, 27, 124-133.

MeYer, D. R., \& MEYER, P. M. (1977). Dynamics and bases of recoveries of functions after injuries to the cerebral cortex. Physiological Psychology, 5, 133-165.

OrbaCh, J., \& FANTZ, R. L. (1958). Differential effects of temporal neocortical resections on overtrained and nonovertrained visual habits in monkeys. Journal of Comparative and Physiological Psychology, 51, 126-129.

Thatcher, R. W., \& Kimble, D. P. (1966). Effect of amygdaloid lesions on retention of an avoidance response in overtrained and nonovertrained rats. Psychonomic Science, 6, 9-10.

Weese, G. D., Neimand, D., \& Finger, S. (1973). Cortical lesions and somesthesis in rats: Effects of training and overtraining prior to surgery. Experimental Brain Research, 16, 542-550.

(Manuscript received January 28, 1984; revision accepted for publication September 8, 1984.) 